\title{
Case analysis of illegal poaching on the waterfowl under highly pathogenic plague in China
}

\author{
By Roller MaMing \\ (Xinjiang Institute of Ecology and Geography, Chinese Academy of Sciences, No. 818 Beijing \\ Road, Urumqi, 830011, Xinjiang, China. E-mail: maming@ms.xjb.ac.cn)
}

\begin{abstract}
China is one of the world's most important countries for waterfowl because of the large amount of potential habitat and its position along major migratory routes. Waterfowl poaching in China is a serious threat, and for over twenty years colleagues and I have tracked waterfowl poaching in China including hunting methods, trade routes and prices involved. According to the latest survey of a NGO, $11.8 \%$ of Chinese people have participated in wildlife consumption, and about $32.0 \%$ of people have seen wildlife consumption (Not necessarily involved in killing and eating the wildlife). The survey results come from 100000 internet questionnaires. The current report provides an update focusing on waterfowl poaching in Xinjiang Province of the northwest China, where is highly pathogenic area on the avian influenza, SARS and the Wuhan coronavirus pneumonia (such as COVID-19). The cases in 2011, 2012, and 2014 involved about 1816 to 2760 birds of more than 20 species, with an estimated total of 200000 wild birds being hunted by a group per year in Xinjiang. Strangely, the poacher was not punished by any law. We know a few waterfowl species are protected as a list of Key Protected Species in China, and hopefully this report will draw attention to the scope of waterfowl poaching in China. China has made great progress with protecting other wildlife, and hopefully more can be done to protect migrating waterfowl.
\end{abstract}

Key words: illegal hunting; waterfowl; a case survey; poisoned; price chain; the west of China

\section{INTRODUCTION}

China is one of the world's most important countries for water birds. China not only many rivers, lakes and other wetland habitat, but major migratory flyways pass over China. Water bird poaching is a serious threat in China, and it has been for a long time. MaMing et al. (from 1998 to 2018) have tracked poaching in many areas of China since 1997 recording the numbers and species of birds killed as well as the hunting methods (see many pictures below), and even information on the transfer from poachers to restaurants.

The novel coronavirus pneumonia from China such as SARS-CoV-2 has erupted in the world in this dark and cold winter and spring. In addition to this, according to Xinhua News Agency the highly pathogenic H5N6 subtype of avian influenza occurred in at least six regions in the first quarter of 2020. It can be said that China is 
a disaster prone country. We want to explain the reasons for the frequent occurrence of plague through wildlife management.

The current report updates instances of poaching in the northwestern province of Xinjiang, China, and updates the hunting methods and prices involved in the illegal trade (MaMing et al. 2012). According to the latest survey from a NGO, $11.8 \%$ of Chinese people have participated in wildlife consumption, and about $32.0 \%$ of people have seen wildlife consumption (Not necessarily involved in killing and eating the wildlife). The survey results come from $100 \quad 000$ internet questionnaires (https://finance.sina.cn/2020-02-21/detail-iimxyqvz4634361.d.html ), involving many endangered species were killed, such as pelicans, storks, geese, swans, cranes, etc. My report will hopefully bring more attention to the scope of the water bird poaching problem in China, especially during the outbreak of highly pathogenic avian influenza, SARS and the novel coronavirus pneumonia such as COVID-19.

Recently, Chinese authorities have closed at least 20000 wildlife concentration farms, which is a step forward. China has made great strides in preventing the poaching of other wildlife such as giant pandas (Ailuropoda melanoleuca) and Tibetan antelope (Pantholops hodgsoni) (e.g. Wei et al. 2015; Buzzard et al. 2012).

\section{SPECIES AND AMOUNTS}

A vast number and incredible diversity including more than 20 species waterfowl have been captured of which, only Common Shelducks, Pintail Ducks, Gadwalls and Ferruginous Pochards are protected in the second class of protected species by the Xinjiang Uygur Autonomous Region (Zhao \& MaMing 2014) (Table 1). For example, on March of 2011 and 2012, respectively, we intercepted 431 and 805 wild waterfowl from Hotan and Aksu in the southern Xinjiang. In April 2012 and July 2014, about 1816 and 2760 wild ducks and geese, respectively, were seized at a duck farm in Anningqu near Urumqi and came from Bosten and/or Wulungu lakes; fortunately, about 580 could be returned to the wild (See the pictures below).

Table 1. The species and amounts of waterfowl are hunted by poachers in Xinjiang

\begin{tabular}{|c|c|c|c|c|c|c|c|c|c|}
\hline \multirow{2}{*}{$\begin{array}{l}\text { Hunting Place } \\
\text { (Season) } \\
\text { Species }\end{array}$} & \multirow[b]{2}{*}{ Scientific Name } & \multicolumn{2}{|c|}{$\begin{array}{l}\text { Hotan } \\
(2011-03)\end{array}$} & \multicolumn{2}{|c|}{$\begin{array}{l}\text { Aksu } \\
(2012-03)\end{array}$} & \multicolumn{2}{|c|}{$\begin{array}{l}\text { Urumqi } \\
(2014-06)\end{array}$} & \multirow[b]{2}{*}{ Total } & \multirow[b]{2}{*}{$\%$} \\
\hline & & No & $\%$ & No & $\%$ & No & $\%$ & & \\
\hline Cormorant & Phalacrocorax carbo & 6 & 1.39 & & & 3 & 0.52 & 9 & 0.50 \\
\hline Swans & Cygnus spp. & & & & & & & $(3+)$ & \\
\hline
\end{tabular}




\begin{tabular}{|c|c|c|c|c|c|c|c|c|c|}
\hline Swan Goose & Anser cygnoid & & & & & & & $(2+)$ & \\
\hline Bean Goose & Anser fabalis & & & & & 1 & 0.17 & 1 & 0.06 \\
\hline Greylag Goose & Anser anser & 3 & 0.70 & 16 & 1.99 & 13 & 2.24 & 32 & 1.76 \\
\hline Shelduck & Tadorna tadorna & 2 & 0.46 & & & 5 & 0.86 & 7 & 0.39 \\
\hline Ruddy Shelduck & Tadorna ferruginea & & & & & 12 & 2.07 & 12 & 0.66 \\
\hline Pintail & Anas acuta & 68 & 15.8 & 264 & 32.8 & 29 & 5.00 & 361 & 19.9 \\
\hline Teal & Anas crecca & 28 & 6.50 & 2 & 0.25 & 16 & 2.76 & 46 & 2.53 \\
\hline Mallard & Anas platyrhynchos & 54 & 12.5 & 30 & 3.73 & 91 & 15.7 & 175 & 9.64 \\
\hline Gadwall & Anas strepera & 40 & 9.28 & 60 & 7.45 & 74 & 12.8 & 174 & 9.58 \\
\hline Spot-billed Duck & Anas zonorhyncha & & & & & & & $(11+)$ & \\
\hline Wigeon & Anas Penelope & 21 & 4.87 & 40 & 4.97 & 7 & 1.21 & 68 & 3.74 \\
\hline Garganey & Anas querquedula & 8 & 1.86 & 2 & 0.25 & 6 & 1.03 & 16 & 0.88 \\
\hline Shoveler & Anas clypeata & 35 & 8.12 & 12 & 1.49 & 13 & 2.24 & 60 & 3.30 \\
\hline Red-crested Pochard & Netta rufina & 53 & 12.3 & 110 & 13.7 & 138 & 23.8 & 301 & 16.6 \\
\hline Pochard & Aythya ferina & 10 & 2.32 & 90 & 11.2 & 12 & 2.07 & 112 & 6.17 \\
\hline Ferruginous Duck & Aythya nyroca & 16 & 3.71 & 29 & 3.60 & 86 & 14.8 & 131 & 7.21 \\
\hline Tufted Duck & Aythya fuligula & 9 & 2.09 & 40 & 4.97 & 2 & 0.34 & 51 & 2.81 \\
\hline Mandarin Duck & Aix galericulata & & & & & & & $(2+)$ & \\
\hline Cranes & Grus spp. & & & & & & & $(4+)$ & \\
\hline Moorhen & Gallinula chloropus & & & & & 2 & 0.34 & 2 & 0.11 \\
\hline Coot & Fulica atra & 12 & 2.78 & 26 & 3.23 & 64 & 11.0 & 102 & 5.62 \\
\hline Others (우) & Ducks (우) & 66 & 15.3 & 84 & 10.4 & 6 & 1.05 & 156 & 8.59 \\
\hline \multicolumn{2}{|l|}{ Total } & \multicolumn{2}{|l|}{431} & \multicolumn{2}{|l|}{805} & \multicolumn{2}{|l|}{580} & \multicolumn{2}{|l|}{1816} \\
\hline
\end{tabular}

\section{POISON BAIT AND PRICE CHAIN}

The waterfowl poachers have little consideration for hunting sustainably by hunting during the breeding season, which is both illegal and inconsistent with traditional customs in China. Traditionally, there were at least 10 ways for hunting in China (Ma Ming et al. 1998, 2012; Liu \& Ma 2007a/b). Because of the government ban on guns since 1993, poisons such as Furadan or Carbofuran, insecticide has become the most common method. The poison is put on food (such as wheat, corn), and when birds ingested the bait they become listless. The hunters then quickly retrieve them and inject Atropine to revive them. During the transportation and fattening period, the birds are fed sedatives to stabilize their mood and prevent self injury.

It is likely that many more birds were poached that went unreported. At 
Anningqu Farm, fifteen hunters had been scattered throughout Xinjiang. According to records they actually captured more than 200000 ducks each year, and more than 600 cages for air transport accommodating 10 to 15 ducks each were present (see pictures below). The poachers have documentation to appear legitimate, such as hunting, raising and transport permits as well as quarantine certificates and business licenses. We know the poaching group collaborated with government officials and benefited from each other (MaMing, 2018).

These cases all come from the same group, and there are hundreds of thousands of such groups around China. Moreover, we know such a huge case has not been severely punished by Chinese law. Given the huge profits involved it is likely the poaching will continue. For example, the purchase price or the price chain from hunters was 25-30 Yuan / a duck (or per kilogram), and air transport 6-8 Yuan / a duck (or per kilogram). In cities of southern China, such as Guangzhou (This city was the origin of SARS), Changsha, Wuhan (Which was the origin of the COVID-19), Nanjing, and Hangzhou et al., the wild duck was sold for 250-300 Yuan at the market and up to 500-900 Yuan in the restaurant (Fig. 1).

China, however, has made great strides in preventing the poaching of other wildlife such as giant pandas and Tibetan antelope (Wei et al. 2015; Buzzard et al. 2012), and hopefully the same can be accomplished with water fowl.

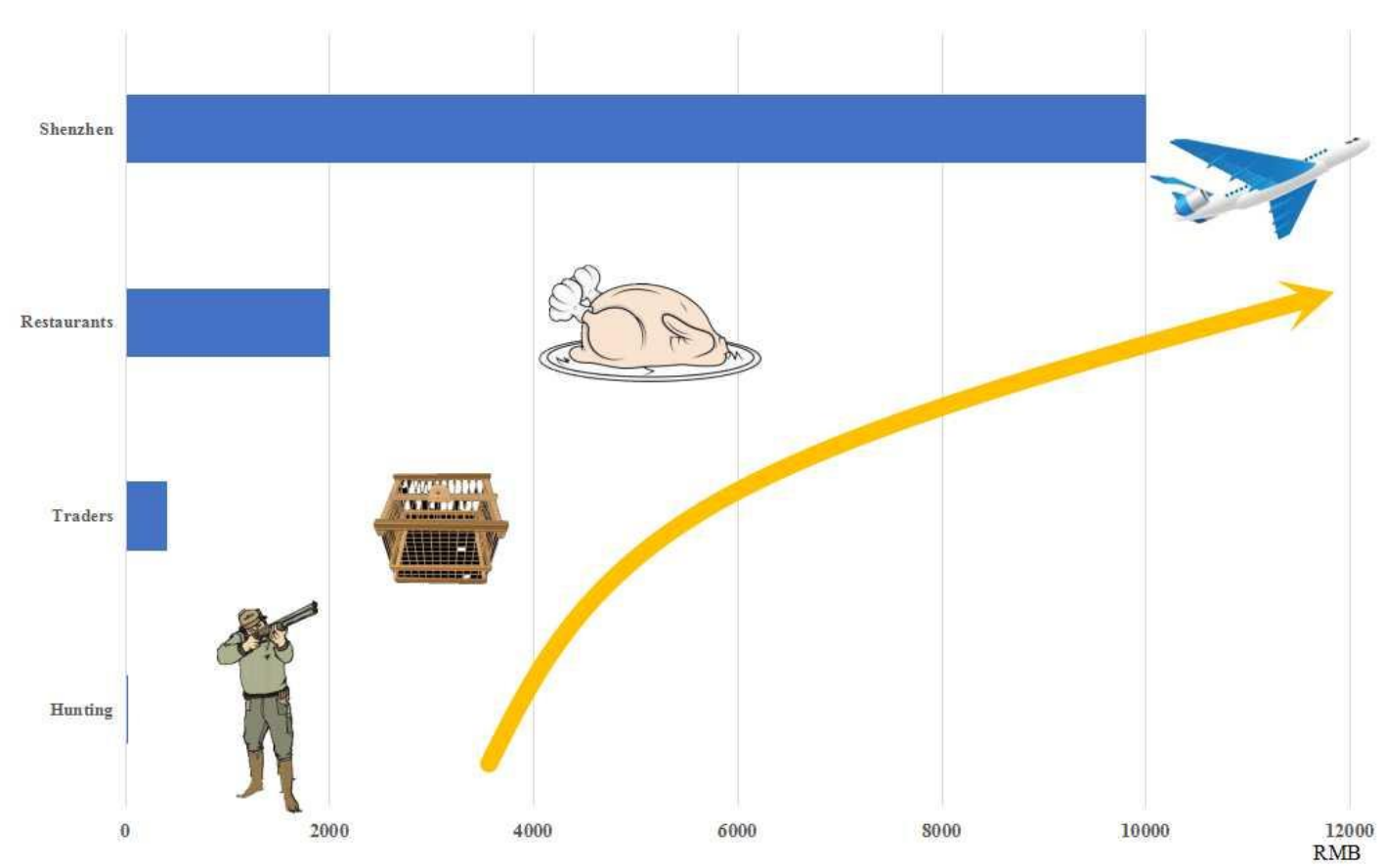

Figure 1. This is a swan's price chain from hunting, fattening, airlifting, trading, and finally to restaurant (Liu \& MaMing, 2017b) 


\section{ACKNOWLEDGEMENTS}

The survey was supported by the National Natural Science Foundation of China (31572292, 31272291, 30970340). I would like to thank Dr. Paul Buzzard, Prof. Ablimit Abdukadir, Liu Xu, Shi Jun and Huang Xiaobao for help in the paper.

\section{REFERENCESE}

Buzzard, P. J., Wong, H. M. \& Zhang, H. B. (2012) Population increase at a calving ground of the Endangered Tibetan antelope Pantholops hodgsonii in Xinjiang, China. Oryx 46(2), 266-268. Liu, X. \& Ma, M. (2017a) Demoiselle Cranes poisoned during migration. China Crane News 21(1): 41-43.

Liu, X. \& MaMing, R. (2017b) Swans killed by poison in China. Swan News 13: 26-31.

Ma, M., Lu, J. J., Tang, C., Sun, P. \& Hu, W. (1998) The contribution of shorebirds to the catches of hunters in the Shanghai area, China during 1997-1998. The Stilt 33: 32-36.

Ma, M. (2000a) Spring migratory cranes were poisoned and the cranes distributed in Xinjiang. China Crane News 4(2): 10-11.

Ma, M. (2000b) Why do Chinese people like to eat waterfowls? Bulletin of the Hong Kong Bird Watching Society 178: 15-16.

Ma, M. (2001) The problems about conservation of wildlife animals in Xinjiang. Arid Land Geography 24(1):47-51.

Ma, M. (2003) Five Demoiselle Cranes were poisoned at Bole, Xinjiang. China Crane News 7(2): 12-13.

Ma M. (2011) A checklist on the distribution of the birds in Xinjiang. Beijing: Science Press.

Ma, M. (2015) Local people hunt migrant birds with vicious methods for a terrible number. Chinese National Geography 66 (11): 141-142.

MaMing, R., Zhang, T., Blank, D., Ding, P. \& Zhao, X. M. (2012) Geese and ducks killed by poison and analysis of poaching cases in China. Goose Bulletin 15: 2-11.

MaMing, R. (2018) Case analysis on hunting wildfowl in Xinjiang, China. China Crane News 22(1): 43-48.

Wei, F. W., Swaisgood, R., Hu, Y., Nie, Y., Yan, L., Zhang, Z., Qi, D. \& Zhu, L. (2015) Progress in the ecology and conservation of giant pandas. Conservation Biology 29(6): 1497-1507.

Zhao, X. M. \& MaMing, R. (2014) The status of Ferruginous Duck Aythya nyroca breeding and wintering in China. Wildfowl 64: 116-125.

Prof. ROLLER MAMING, Key Laboratory of Biogeography and Bio-resource in Arid Land, Xinjiang Institute of Ecology and Geography, Chinese Academy of Sciences, No. 818 Beijing Road, Urumqi, 830011, Xinjiang, China.

E-mail: maming@ms.xjb.ac.cn

MaMing's blogs about illegal poaching in Sciencenet: http://blog.sciencenet.cn/blog-2048045-847539.html http://blog.sciencenet.cn/blog-2048045-1102053.html http://blog.sciencenet.cn/home.php? $\bmod =$ space $\&$ uid $=2048045 \& \mathrm{do}=$ blog $\&$ view $=$ me $\&$ from $=$ space \&page $=4$ 


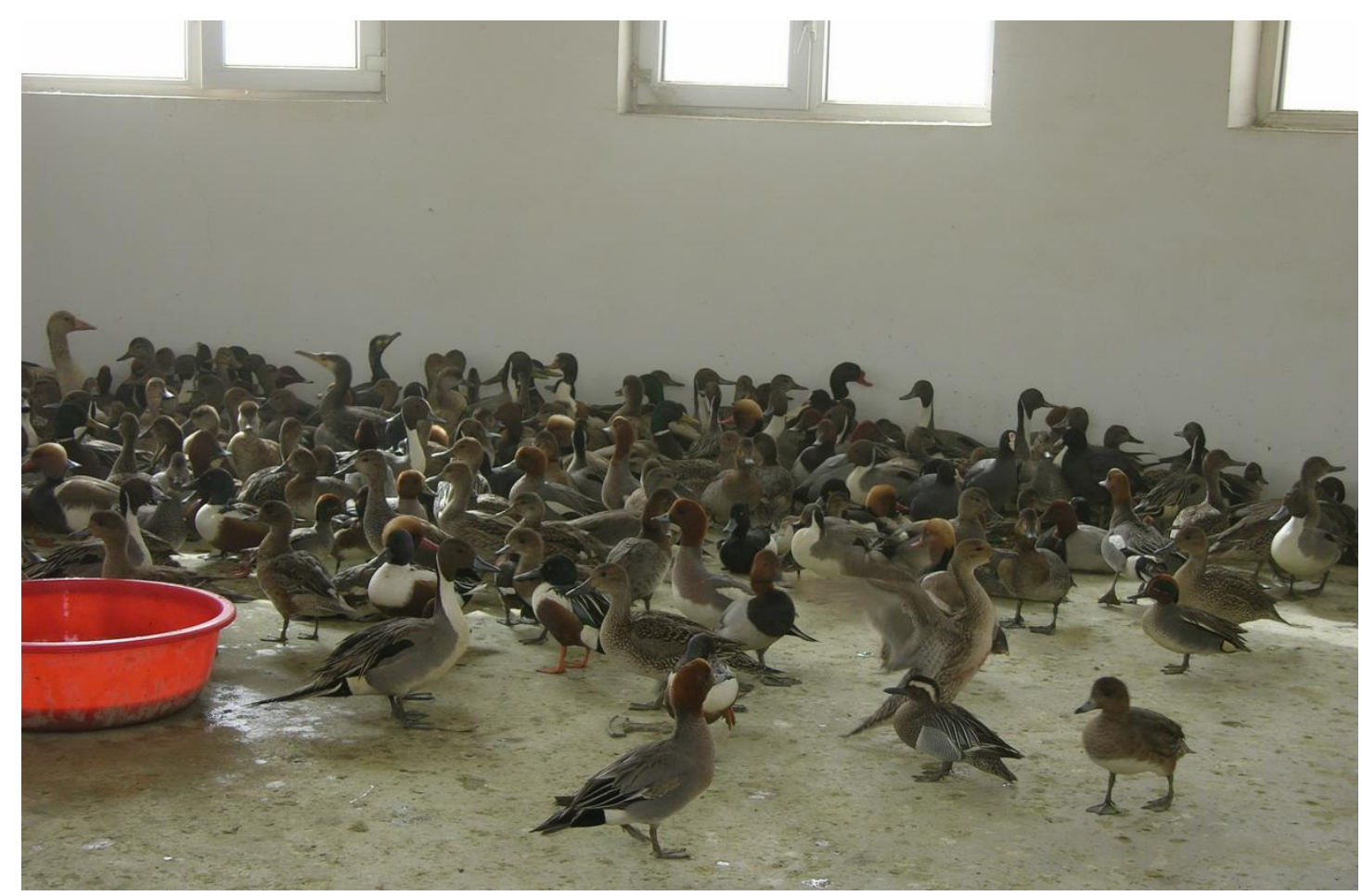

This case and all our stories come from the same group, who followed the migration of waterfowl to all over China. Their entire case group has been prosecuted. Why hasn't they been sentenced? Because they have legal procedures, they openly say that the thousands of wild ducks above are bred and raised by them in the farm. Do you believe that? But, the judges in Beijing believed it.

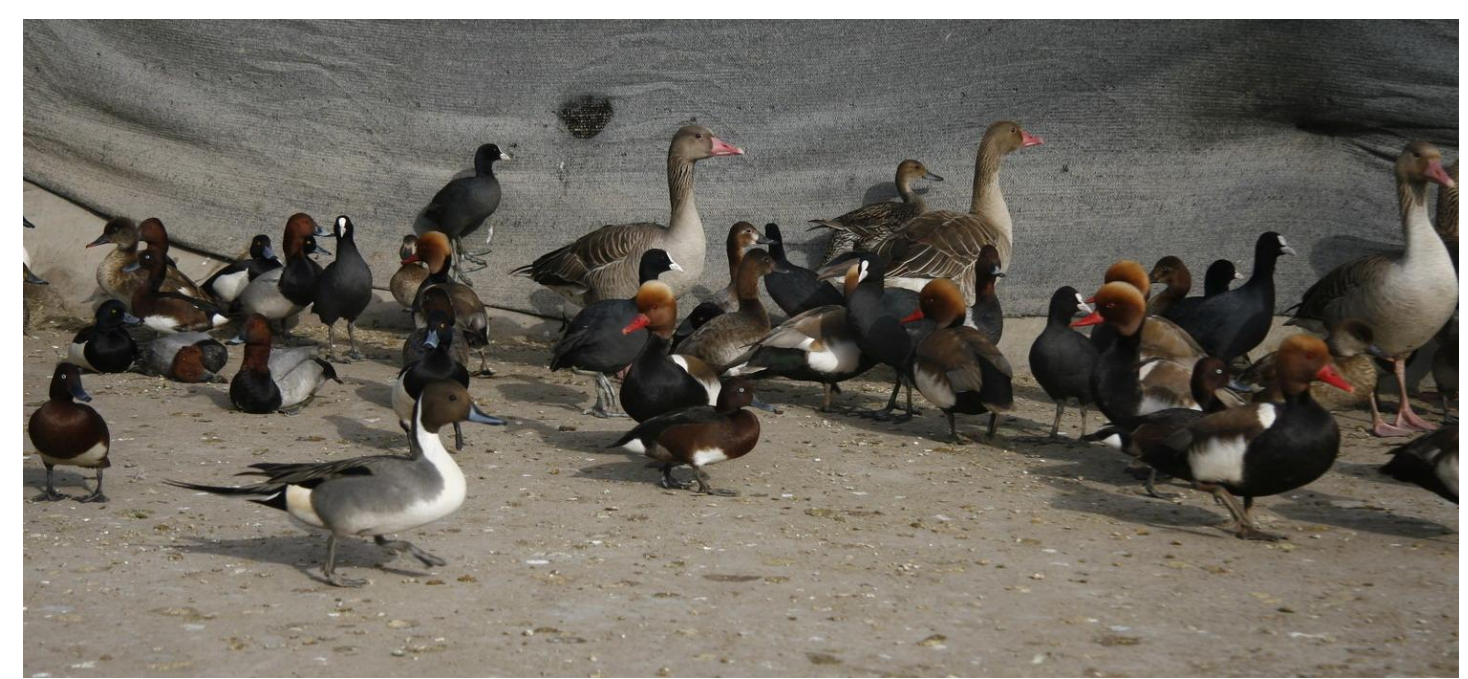

As you know, Chinese people like to eat wild birds, especially those from the western Xinjiang, without environmental pollution and so on. And poachers take advantage of loopholes in the law and management is not in place, openly trafficking, trading, processing and selling. From the whole price chain analysis, it is profitable.

(Photo by MaMing from a farm in the south of Xinjiang, the west of China) 


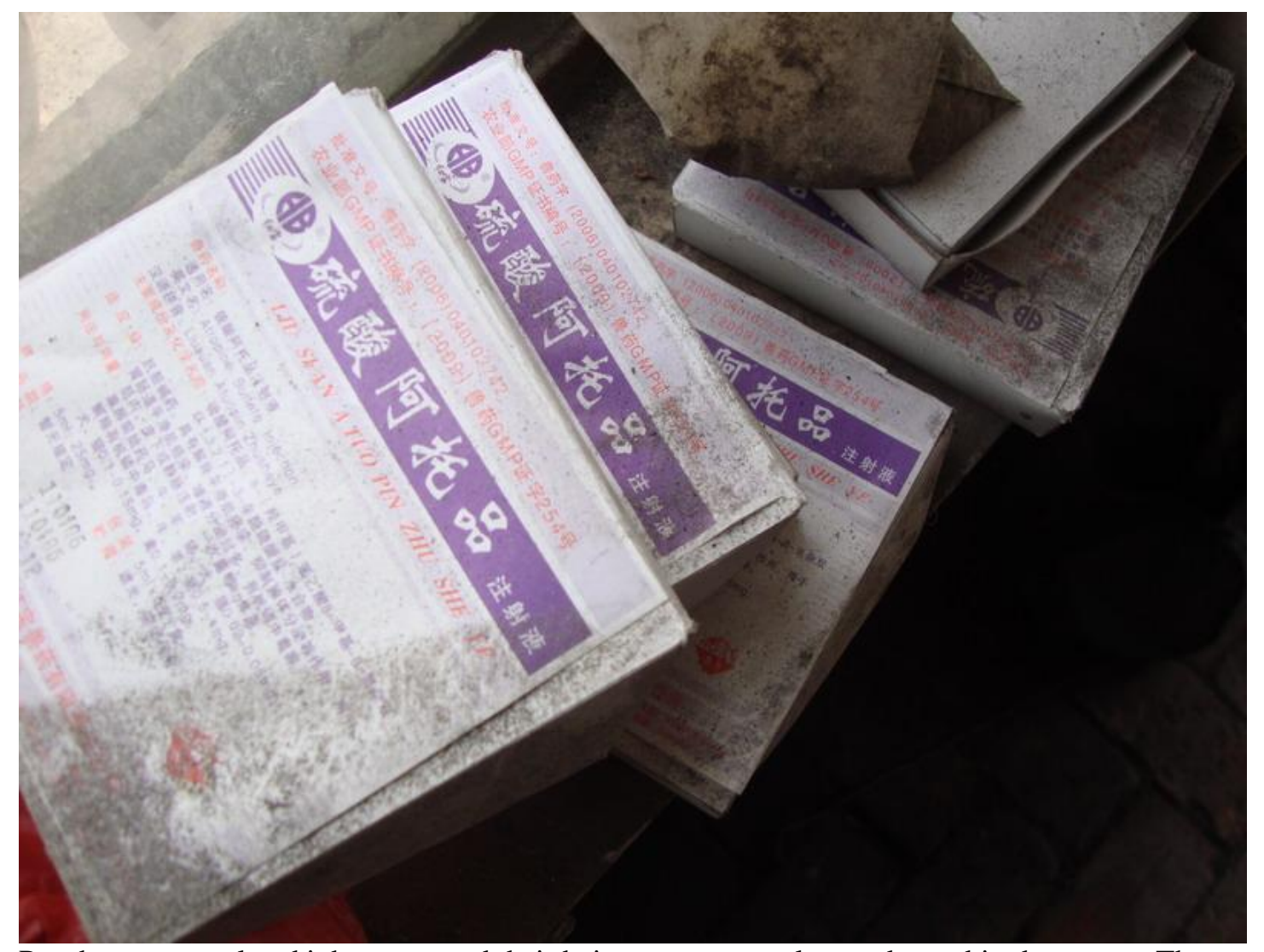

Poachers are cruel and inhumane, and their bait costs are very low and very big dangerous. These drugs are uncontrolled, with more than 20 kinds of birds of poisoning, including China's state-protected species, such as pelican, stork, crane, goose and swan etc. No one may want to see this excessive hunting and killing of innocent, inhuman. As you all know, the Chinese government has been very successful in gun control, and the recovery of wildlife populations is obvious.

However, with the relaxation of management, various poaching cases have an increasing trend. And according to the wisdom of the Chinese people, the methods of hunting emerge endlessly. (Photo by MaMing)

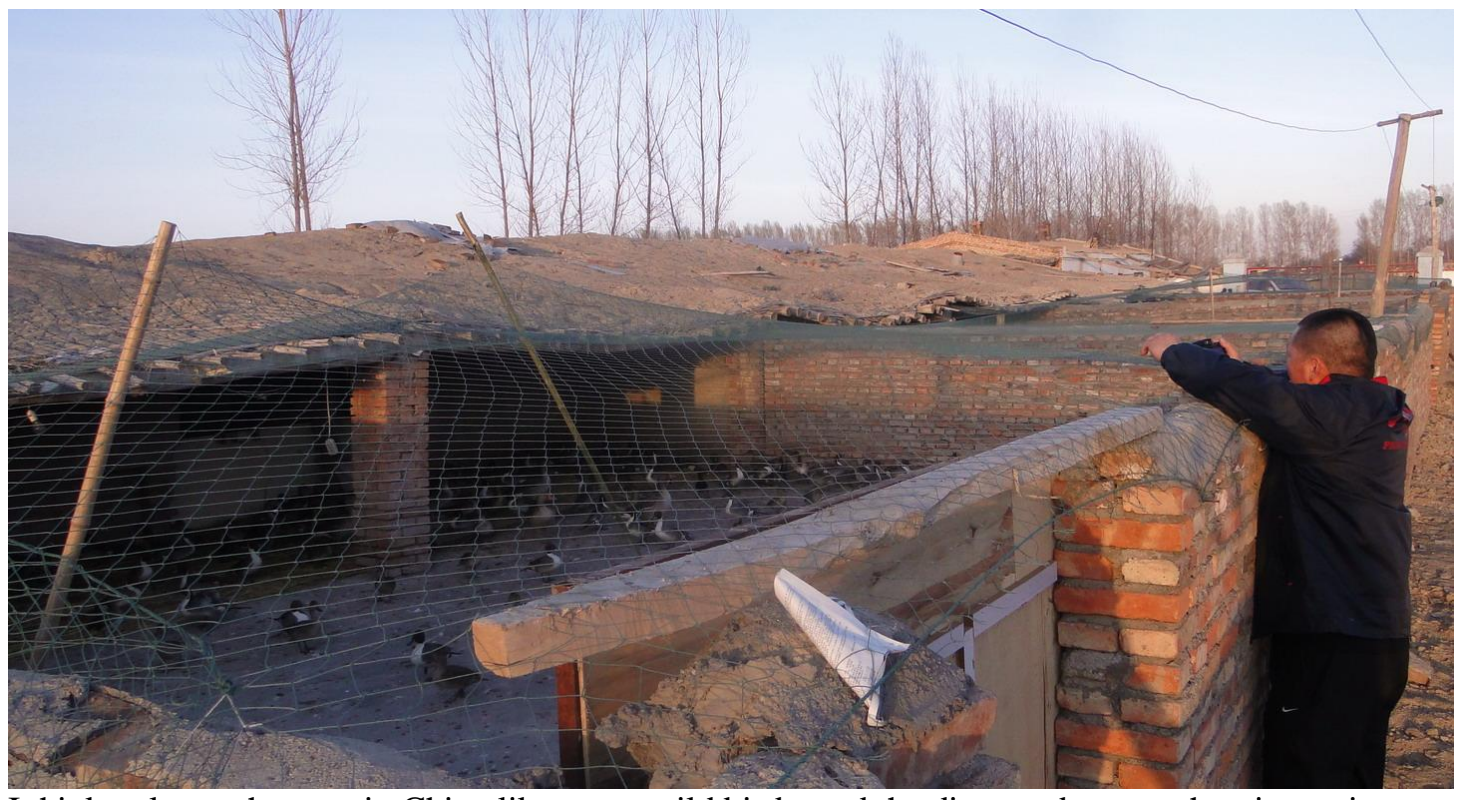

I think only southerners in China like to eat wild birds, and the distance between hunting point and transportation from north to south is $3000 \sim 5000 \mathrm{~km}$. There should be countless checkpoints and health inspection departments along the way. But every department is a green light. 
According to the statistics of aviation documents, they transport more than 200000 wild birds in Xinjiang every year. However, elsewhere in China, the number is more than 20 million per year. (Photo by MaMing from the local wildlife farm near Urumqi, Xinjiang, the west of China)

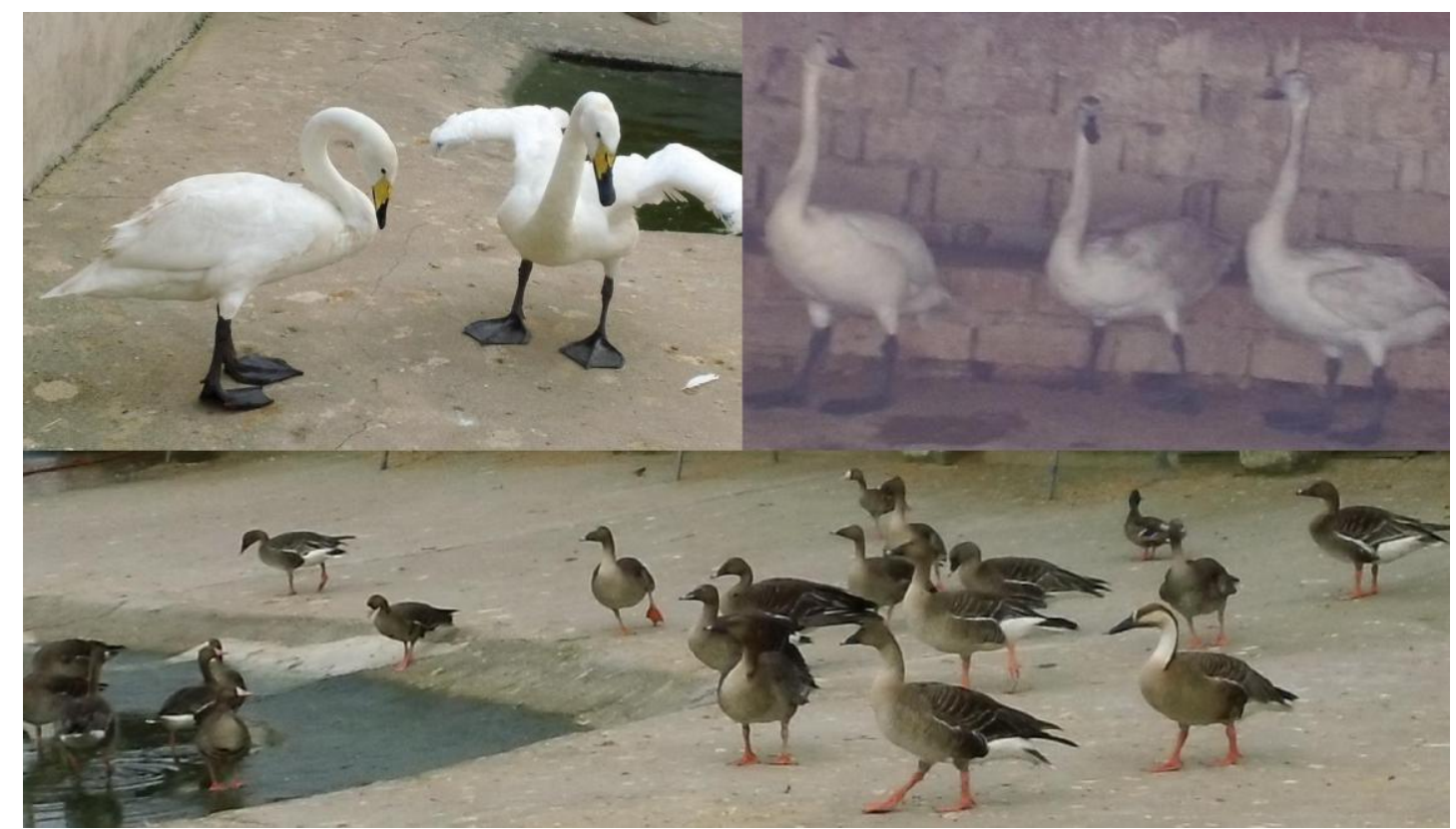

Poachers are cruel and inhumane, and they do not selectively capture species, including China's state-protected species, such as some pelicans, storks, cranes, geese and swans. Through this report, we hope to introduce a case objectively, expose the true situation of poaching, and warn the world to pay attention to China's poaching and legal progress. It is obviously impossible for us to publish such a report in China, because it is dark and ugly. At present, many of the Chinese reports you have seen (from 1998 to 2018 by Ma et al.) are basically internal communications and briefings in the Newsletters of Chinese Ornithological Society, which lack social influence and have no any effect on publicity and education.

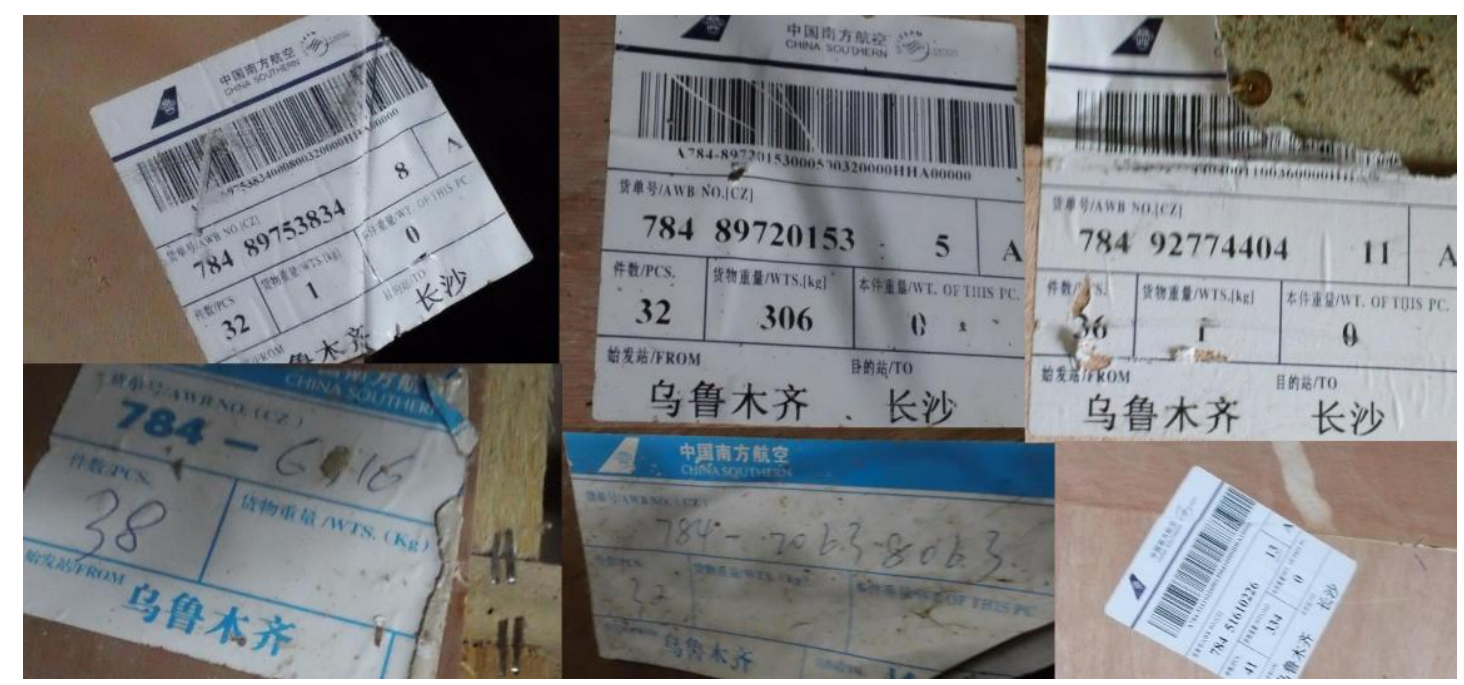

These are the airline's transport documents. The freight is very cheap in China, only 6-8 yuan (6.30 yuan $=1.00$ \$US) per duck or one kilogram. These cases all come from the same group, and there are hundreds of thousands of such groups around China. It is estimated that the number of poachers is very large, and the shocking number exceeds 20 million birds per year in China. 


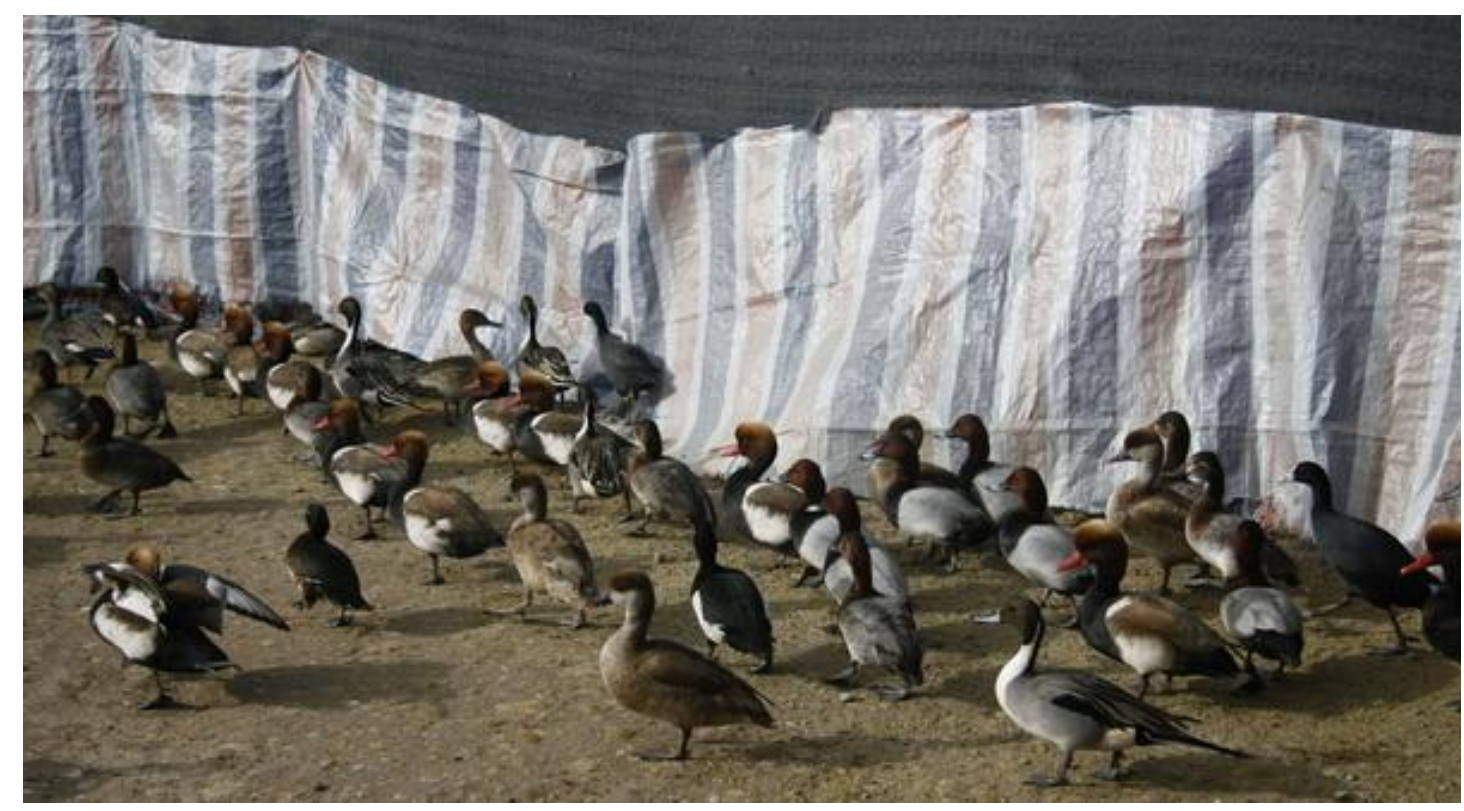

Poachers are cruel and use a lot of poison bait, which not only harms wild birds, but also harms buyers. Every year in China, there are some cases of poisoning involving children and the elderly. The waterfowl poachers have little consideration for hunting sustainably by hunting during the breeding season, which is both illegal and inconsistent with traditional customs in China. Traditionally, there were at least 10 ways for hunting in China (MaMing et al. 1998/2012). Because of the government ban on guns since 1993, poisons such as Furadan or Carbofuran, insecticide has become the most common method. They put the poison on food (such as wheat, corn), and when birds ingested the bait they become listless. The hunters then quickly retrieve them and inject Atropine to revive them. During the transportation and fattening period, the birds are fed sedatives to stabilize their mood and prevent self-injury.

(Photo by Prof. MaMing from a farm in Xinjiang, the west of China)

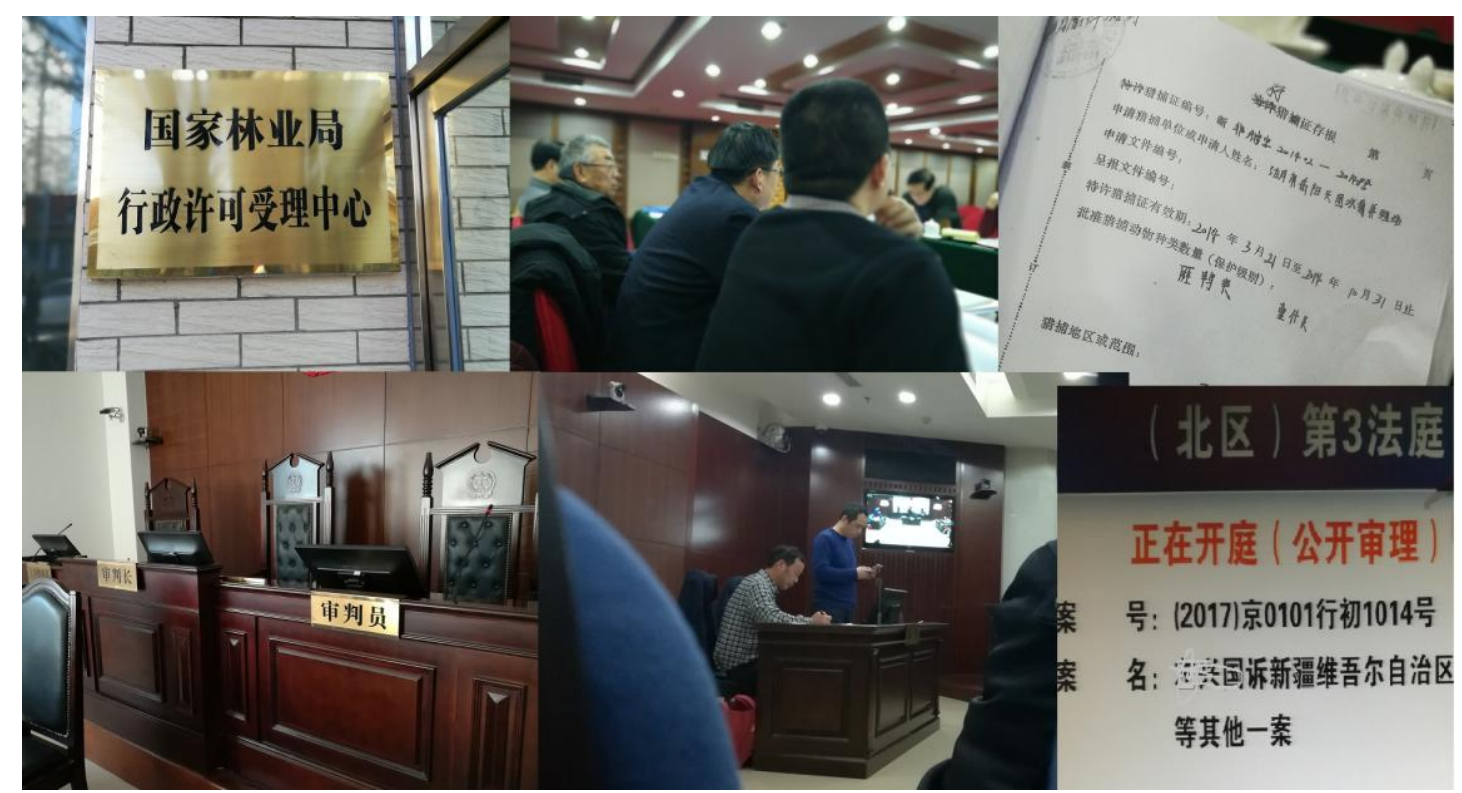

As an observer and scientific witness of this case, from 2012 to 2020, I paid close attention to the process of the trial (MaMing et al. 2012; MaMing, 2018). I went to the poaching scene for statistics and identification, and took a lot of evidence. I am also one of the four witnesses to the expert testimony of scientists in Beijing. As an ornithologist and a professor of zoology, I feel humiliated and very sad. The end result was that the judge said we had insufficient evidence and that the offender had not been punished. (Photos by Prof. MaMing in a court, Beijing) 


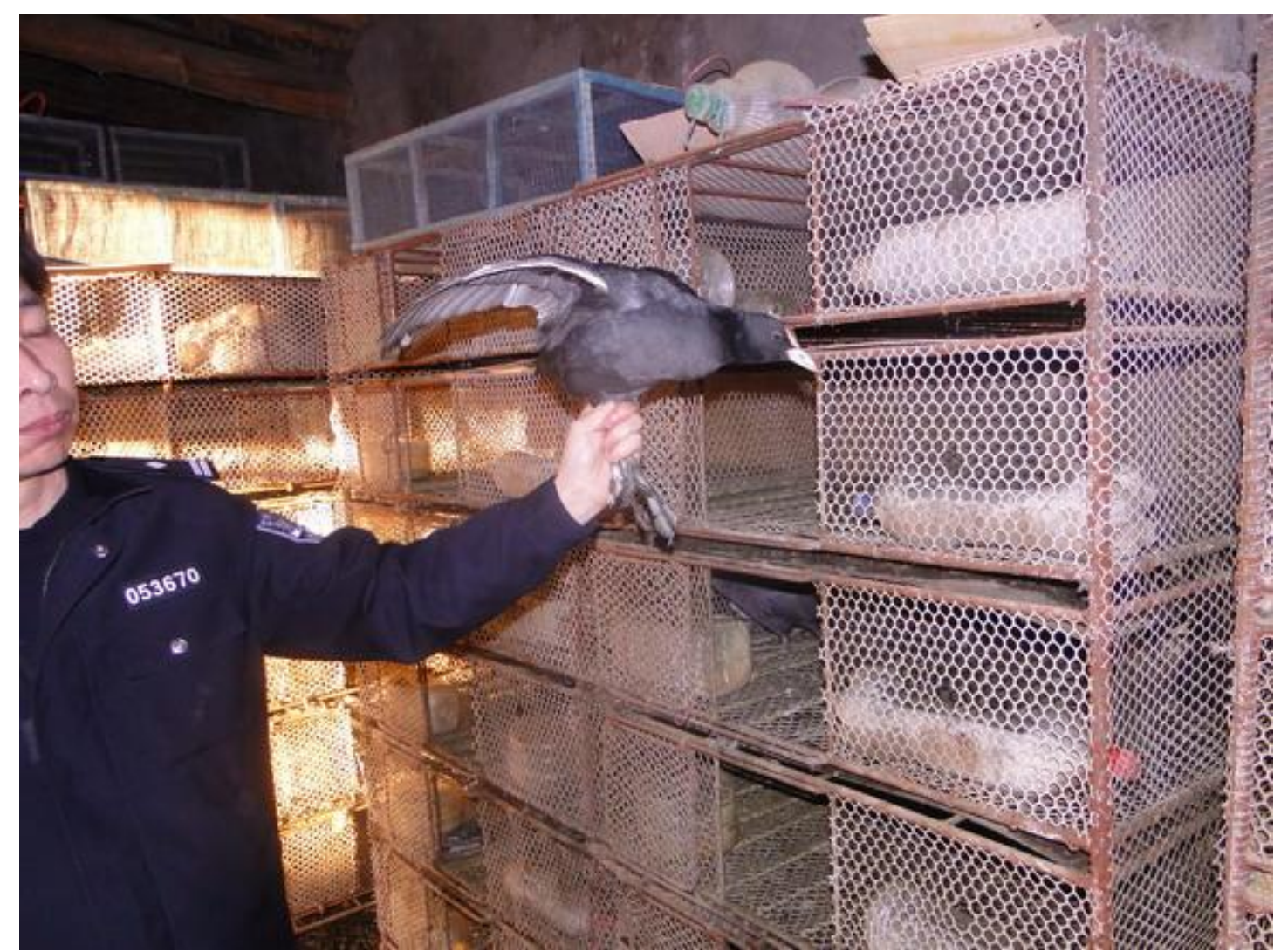

These are airborne cages. We found that there are about 600 cages in one place. Freight is very cheap in China, it is only 6-8 yuan (about 1 US\$) per duck or a kilogram. It is estimated that the number of poachers is very large, and the shocking number exceeds 20 million birds per year in China. (Photo by Prof. MaMing from a farm near Urumqi, Xinjiang, the west of China)

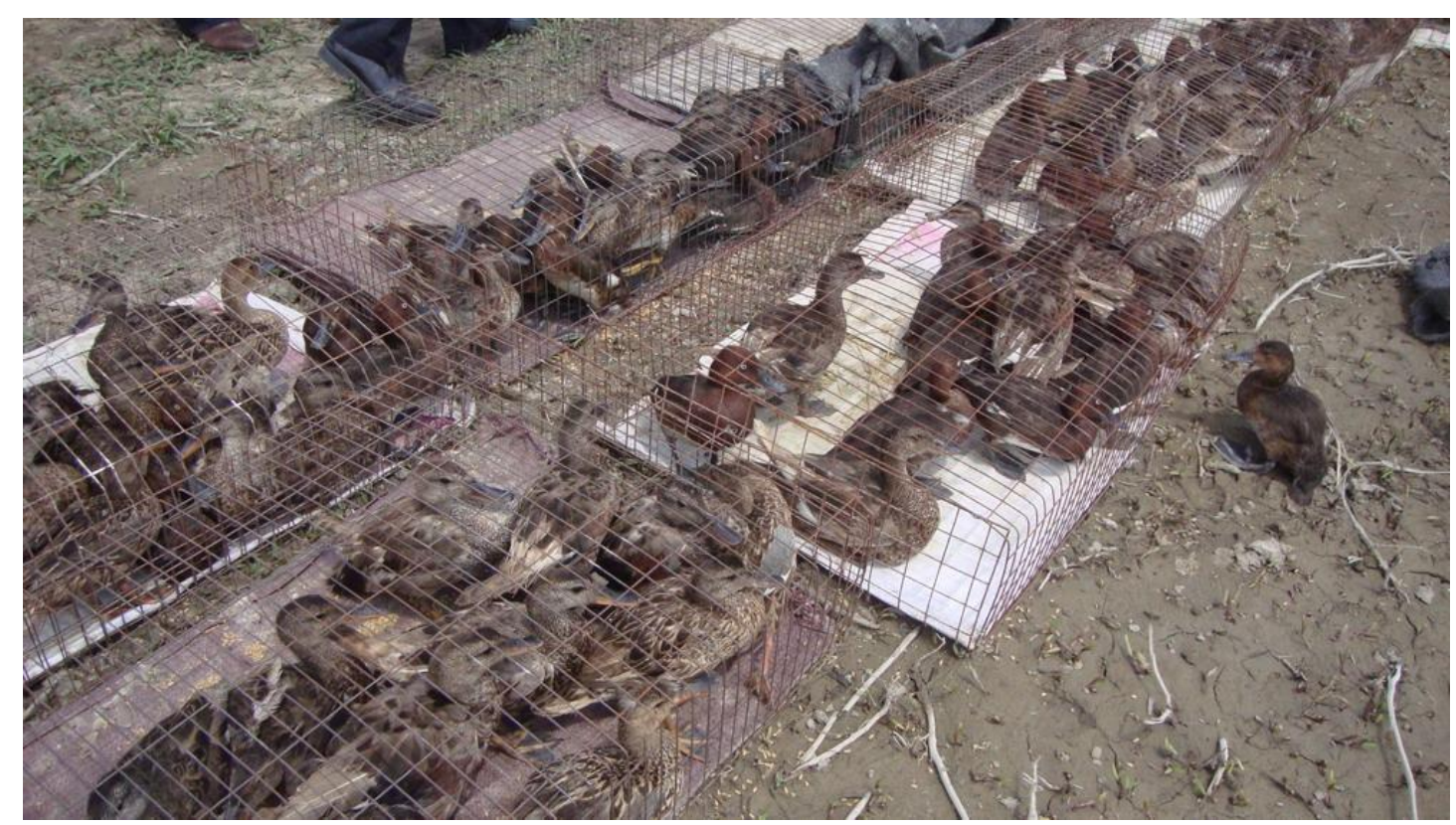

The case was delayed for five years (from 2014 to 2019), which made us incredible. In the end, the criminals were not punished by the Chinese law. The one reason is that we have no evidence that these are wildlife! (Photo by MaMing from Wujiaqu, Xinjiang, the west of China)

Note: there are many Ferruginous Ducks (Aythya nyroca) in these cages, all of which are internationally endangered (Table 1). 


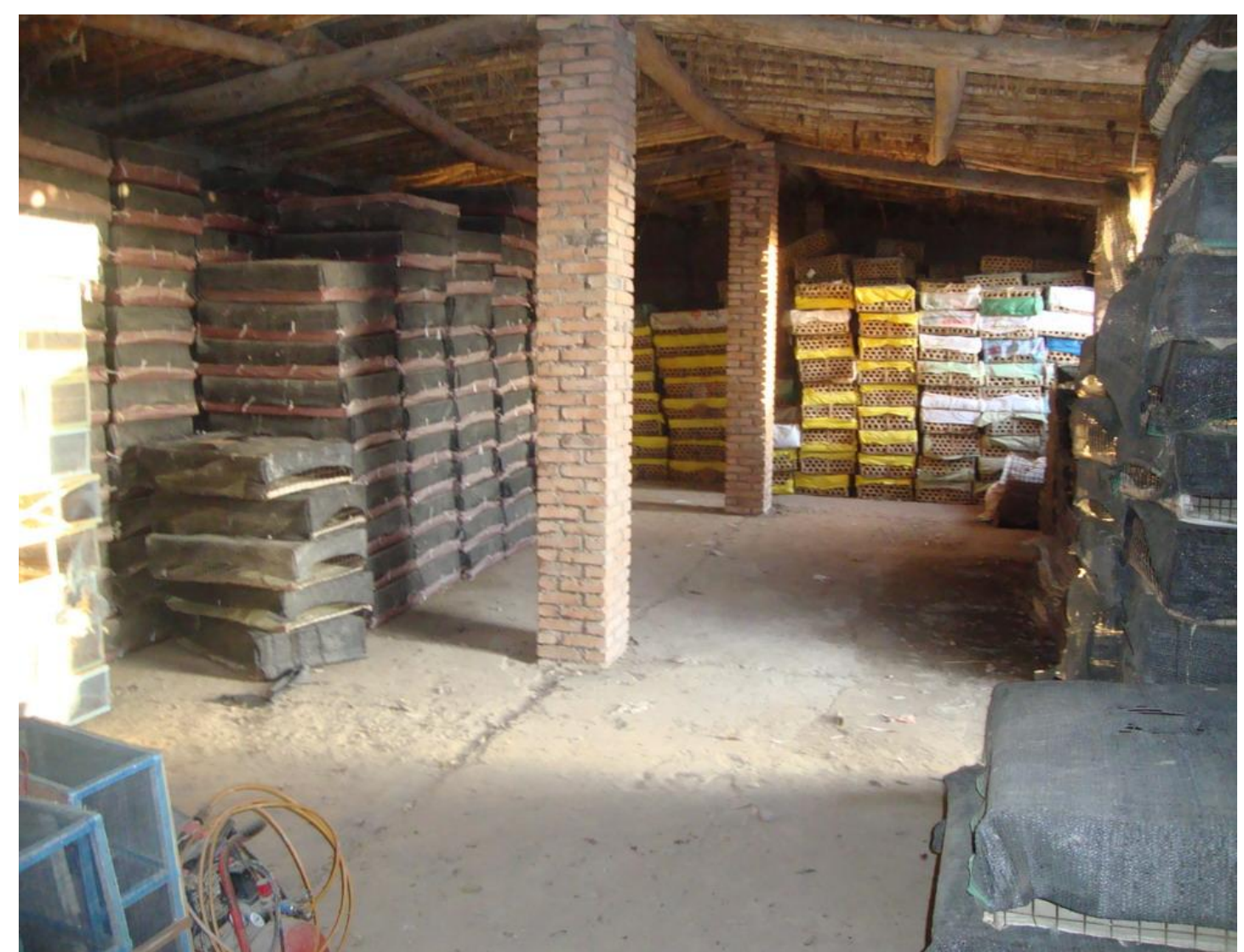

These are loading wild duck cages, each cage average only accommodate 10 wild ducks, and the 600 cages are for 6000 ducks only one time for transport. China's laws are weak and they think wild ducks should not be protected. China's geographical location is located in the migration area, the breeding area in the north and the wintering area in the south. Therefore, poachers are seasonal in their activities. They follow the migratory path of wild birds and hunt them. It is difficult to find and catch them. In China, where the plague is rampant in the early 2020, at least five sites have detected the highly pathogenic avian influenza H5N6 subtype in wild swans in this terrible and dark winter.

(Photo by Prof. MaMing from a farm near Urumqi, Xinjiang, the west of China) 